\title{
Study of Malt Bagasse Biomass as Biosorbent for Acetic Acid Removal in Effluents
}

\author{
Thiago Reixach Pires de Souza, Wilson Sacchi Peternella* \\ Department of Chemistry, Federal University of Rondônia, Campus José Ribeiro Filho, Porto Velho, Brazil \\ Email: *wpeternella@yahoo.com
}

How to cite this paper: de Souza, T.R.P. and Peternella, W.S. (2021) Study of Malt Bagasse Biomass as Biosorbent for Acetic Acid Removal in Effluents. Open Access Library Journal, 8: e7478.

https://doi.org/10.4236/oalib.1107478

Received: April 30, 2021

Accepted: May 24, 2021

Published: May 27, 2021

Copyright $\odot 2021$ by author(s) and Open Access Library Inc.

This work is licensed under the Creative Commons Attribution International License (CC BY 4.0).

http://creativecommons.org/licenses/by/4.0/

\begin{abstract}
In the present work, the biomass known as the malt bagasse, a by-product of the brewing industry, was studied as a biosorbent of acetic acid, in order to evaluate its potential use as an ion exchanger in effluent treatment systems. The process is based on the phenomenon of biosorption, an interface phenomenon, which is the natural accumulation of a solute on the surface of a solid. The studied phenomenon is that of acetic acid adsorption in malt bagasse biomass. In the present work, the influence test of the biomass quantity was carried out, and it was verified that $40 \mathrm{~g} / \mathrm{L}$ is the ideal concentration of malt bagasse in the acetic acid adsorption process. A kinetic study was also carried out, where a contact time of 20 minutes was defined to reach the balance between the solid/liquid phase. In the identification of the pseudo-second order kinetic model, it was the one that best fitted the experimental data, and based on the intra-particle diffusion model, it was found that more than one step comprises the biosorption mechanism, with intra-particle diffusion being limiting step. Based on this information, the chemical equilibrium test of the solid/liquid phase was performed using the mathematical models of Langmuir and Freundlich, thus presenting, for the malt bagasse, a maximum acetic acid adsorption capacity of approximately $30 \mathrm{mg} / \mathrm{g}$. Where experimental data best fit the Langmuir isotherm. The results show a significant potential for the malt bagasse to remove organic acid in effluents.
\end{abstract}

\section{Subject Areas}

Environmental Sciences

\section{Keywords}

Malt Bagasse, Biomass, Adsorption, Acetic Acid, Effluents 


\section{Introduction}

The growth of cities together with population growth and technological development is a reality today. However, environmental problems related to the generation of waste due to the increased demand for consumption by the population have accompanied this population growth. Mainly problems are related to the increase in the discharge of effluents in water resources, which are of vital importance for life on our planet. Pollution of water resources, especially fresh water, whether underground or surface, is of great concern today. That is why, more and more stringent laws related to the control of the discharge of effluents into aquatic ecosystems are being approved and applied.

Effluents are generated every day by all sectors of society, thus, these effluents are classified into two types: domestic effluents, which are generally generated by households, and industrial effluents, which are generated by industries, and are the effluents from the production process. As described by (Cammarota, 2011) [1], an industrial effluent is, in general, the result of the mixture of different currents generated in different units of the production process.

It is known that industries are the main sources of discharge of effluents into water bodies, as they produce large volumes of effluents with high polluting loads on a daily basis (Silveira, 2010) [2].

Currently, the main parameter that quantifies the polluting load of an effluent is the values of Chemical Oxygen Demand (COD) and Biological Oxygen Demand (BOD). The chemical oxygen demand, measures the oxygen consumption that occurred during the chemical oxidation of organic matter in a substrate. Whereas the biochemical oxygen demand, establishes the amount of oxygen needed to biologically stabilize the carbonaceous organic matter, at $20^{\circ} \mathrm{C}$, after 5 days according to (Izquierdo, 2006) [3], that is, the COD and BOD values are parameters related to the polluting load in terms of organic matter.

Effluents of industrial origin, with their high organic matter load, that is, high COD and BOD, present great risks to the environment if released without a previous treatment to the receiving body. Such effluents can cause a decrease in the rate of dissolved oxygen in lagoons and rivers, causing the death of the local aerobic biota, in addition to causing their eutrophication, among many other environmental problems. In terms of BOD, an industry, before discharging its effluent into a receiving body, must promote, according to CONAMA Resolution No. 430/2011 [4], the minimum removal of $60 \%$ of BOD, should be promoted. This limit is only that it may be reduced in the case of a self-purification study of the water body that proves compliance with the goals of framing the receiving body.

Industries, in order to meet these effluent discharge parameters, can use several technologies, which may vary according to the effluent parameters they generate. Among the most used technologies for effluent treatment, one can mention the activated sludge system and the Australian pond systems. In addition to these technologies, in tertiary treatment, which consists of a series of 
processes aimed at improving primary and secondary treatments, they can operate the processes of filtration, adsorption with activated carbon, ion exchange, reverse osmosis and chemical oxidation, as described by (Cammarota, 2011) [1]. However, these technologies used in tertiary treatment to improve the parameters of the effluent, require large economic investments or even demand a lot of energy, and end up becoming unfeasible. An alternative to improve the removal of COD in industrial effluents is the use of biosorption, which uses biomass as a biosorbent, promoting the removal of COD from effluents. In this way, biosorption could be used as a way to increase the efficiency of wastewater treatment systems, and also reduce costs in its process.

Adsorption is an interface phenomenon, which occurs due to asymmetric forces present on the surface of a solid, and which generate an attractive force field (Adamian, et al. 2002) [5]. Adsorption is a mass transfer phenomenon, which involves the ability of certain solids to concentrate some substances present in fluids on their surface, allowing the separation of the components of this fluid (Nascimento, et al. 2014) [6]. The adsorption process can be classified into two types according to the forces that govern it. The first type is physical adsorption, which involves weak interactions in the adsorbate adsorption process on the surface of the adsorbent solid, related to Van der Waals forces (Nascimento, et al. 2014) [6]. The second type is chemical adsorption, where the adsorbent joins the surface of the adsorbent through the formation of chemical bonds and tends to accommodate in places that provide the maximum number of coordination with the substrate (Atkins, et al. 2002) [7]. These two processes are independent, and have different characteristics. Chemical adsorption is highly specific, occurring at active sites present on the surface of the adsorbent, and a substrate must have a specificity to bind to these sites, a characteristic that allows the formation of an adsorbate monolayer on the adsorbent. Physical adsorption is non-specific, that is, of an electrostatic nature, a characteristic that allows the formation of several layers of the adsorbent on the surface of the adsorbent (Nascimento, et al. 2014) [6].

The adsorption process generally involves four main steps: 1) transport of the solute in the solution, fast phenomenon "diffusion/convection", 2) external layer, where mass transfer occurs "external diffusion", 3) diffusion intra-particle in the pore a) and diffusion in the surface b) and 4) instant adsorption, as described by (Wang et al. 2008 apud Fontana, et al. 2016) [8], conform indicate in Figure 1.

As described by Peternele (1999) [10], the results of any adsorption process are expressed graphically in the so-called adsorption isotherms, which provide important information about an adsorption phenomenon. Different adsorption mechanisms give rise to different isotherms (Adamian, et al. 2002) [5]. Several forms of isotherms are described in the literature, with the most common types being concave, linear, convex and irreversible isotherms (Zanutto, et al. 2016) [11] as shown in Figure 2. 


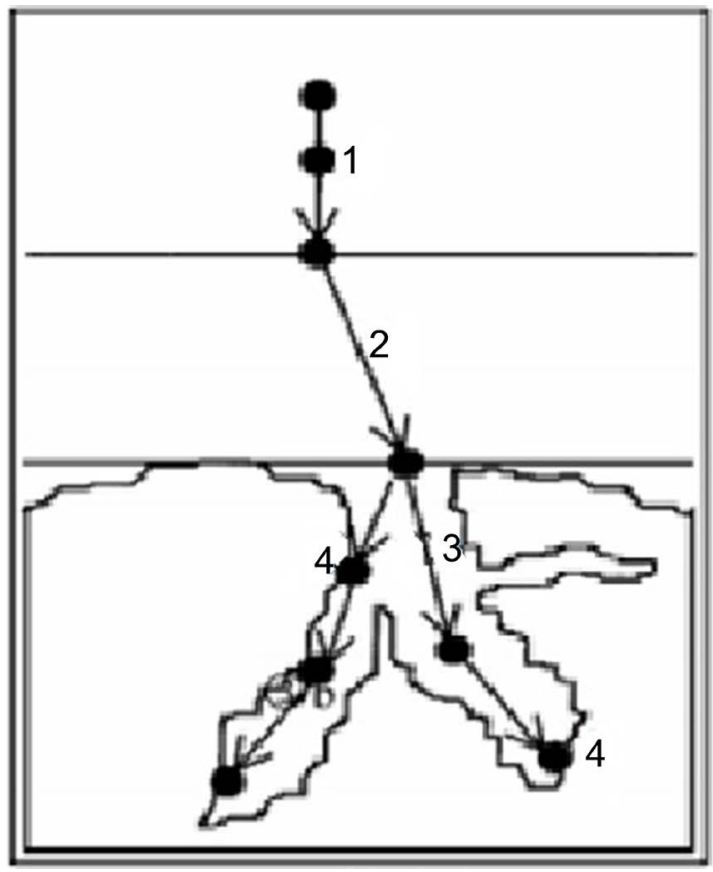

Figure 1. Steps of the adsorption mechanism. Source: Weber and Smith, 1987 [9].

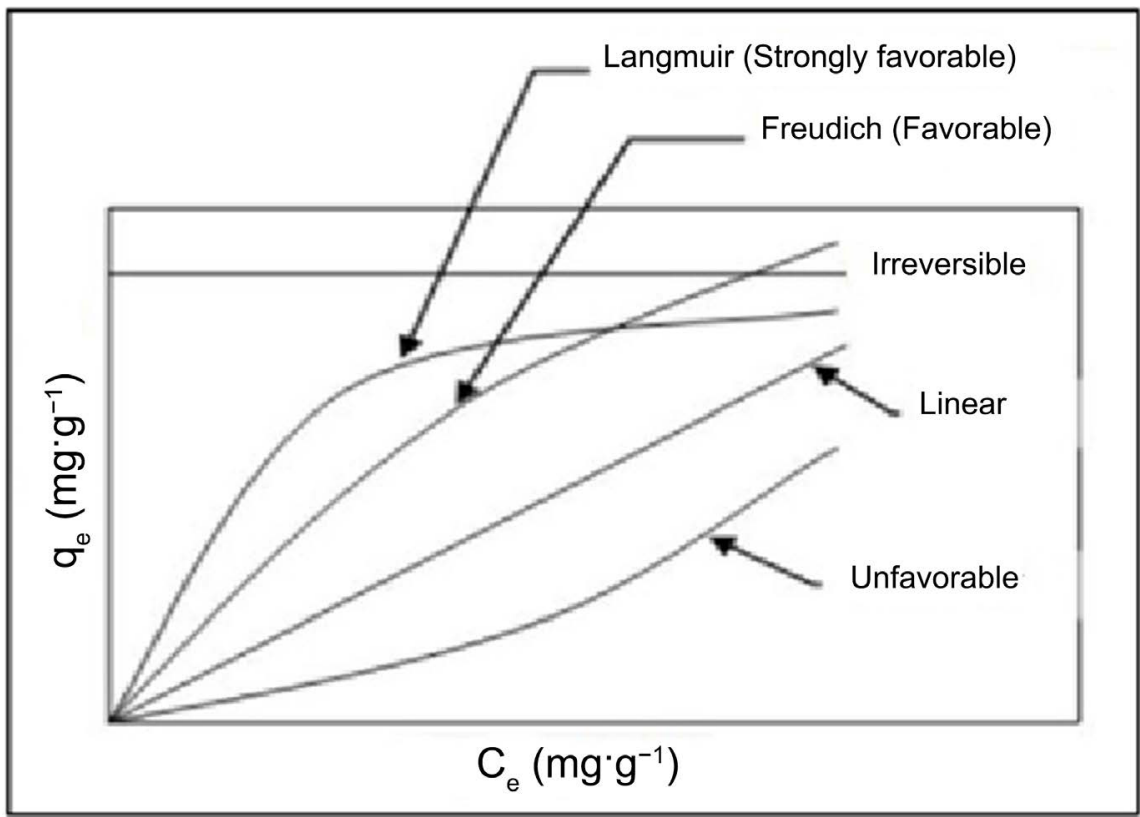

Figure 2. Adsorption isotherms. Source: Oliveira, 2013 [12].

The Langmuir model (1918) [13] is one of the most widely used and widespread adsorption isotherm models. As described by Adamson (1976) [14], this adsorption process is based on some hypotheses: 1) the adsorption is limited to one layer; 2) the surface of the adsorbent is homogeneous energetically and has a number of finite adsorption sites; 3 ) the adsorbed molecules do not interact with each other and 4) for a case of competitive adsorption of different species, the enthalpy of adsorption is the same for all molecules. The Langmuir isotherm can 
be represented in a non-linear form, for a solid-liquid interface, according to Equations (1) and (2):

$$
\frac{q}{q_{m}}=\frac{K_{L} \cdot C_{e}}{1+K_{L} \cdot C_{e}}
$$

Or, in its linear form, in 2 :

$$
\frac{C_{e}}{q}=\frac{1}{K_{L} \cdot q_{m}}+\frac{C_{e}}{q_{m}}
$$

where: $C_{e}$ concentration of the solution in equilibrium in $\left(\mathrm{mg} \cdot \mathrm{L}^{-1}\right), q$ corresponds amount adsorbed in $\left(\mathrm{mg} \cdot \mathrm{g}^{-1}\right), K_{L}$ a constant indicating the intensity of adsorption in $\left(\mathrm{L} \cdot \mathrm{g}^{-1}\right)$ and $q_{m}$ a measure of the maximum adsorption capacity.

The Langmuir model, although widely used, is very restricted, due to the number of hypotheses attributed to it, which in some cases are not verified, such as, for example, the hypothesis of not considering interactions between species of adsorbate and the energetically homogeneous surface. Thus, other models such as Freundlich's, in order to obtain a model closer to chemical observation, not considered by the Langmuir model.

The Freundlich model (1906) [15], is based on hypotheses that better portray physical phenomena, better represents physical adsorption with the possibility of multilayer formation (Castellan, 1976) [16], represented by Equations (3) and (4).

$$
q_{e}=K_{F} \cdot C_{e}^{\frac{1}{n}}
$$

where: $q_{e}$ and $C_{e}$ correspond to the same variables in the Langmuir equation;

$K_{F}=$ the Freundlich constant in $\mathrm{L} \cdot \mathrm{g}^{-1}$ and is related to the maximum adsorption capacity; and

$1 / n=$ a dimensionless exponent, has a value less than 1 , and is related to the intensity of adsorption.

The Freundlich equation in linear form, follows the logarithmic property.

$$
\log q_{e}=\frac{1}{n} \cdot \log C_{e}+\log K_{F}
$$

In the Freundlich model there is no association or dissociation of the molecules after they are adsorbed on the surface and there is also a complete absence of chemosorption, that is, the adsorption process is purely physical (Noll, et al. 1992) [17].

Biosorption is a complex term, but it can be simplified as the process of removing substances from a solution by a material of biological origin (Gadd, 2009) [18]. The process uses biomass as an adsorbent, which makes the cost of treating effluents more accessible. This process includes the retention of both heavy metals and organic compounds to the biomass used (Zanutto, et al. 2016) [11]. As with any adsorption process, it depends on some factors such as $\mathrm{pH}$, adsorbent concentration, type of adsorbent used (in the case of biosorption, type of biomass used), and the contact time between the initial solution and the ad- 
sorbent. The biosorption phenomenon occurs due to the presence of several functional groups that make up the biomass, such as cellulose, polioses, proteins and lignin.

There are some desirable characteristics for a biosorbent, such as: high surface area for greater adsorption capacity, high selectivity, favorable kinetic interaction with the adsorbate, being chemically and thermally stable, possessing the minimum of solubility, hardness and mechanical resistance to avoid the pore strangulation and particle wear, not having a tendency to form undesirable reactions, and above all low cost (Oliveira, 2013) [12].

Low-cost biomass, malt bagasse is the most abundant by-product in the brewing industry, corresponding to about $85 \%$ of the total by-products generated (Mussatto, et al. 2006) [19]. Malt bagasse is obtained after the malted cereal grinding process, followed by maceration and filtration of the brewing wort. Currently, this waste does not have a specific destination, being most often used for animal feed (Cordeiro, et al. 2012) [20].

Malt bagasse has enormous prominence in the possibility of being a useful biosorbent for the removal of contaminants in wastewater (Fontana, et al. 2016) [8]. As for its composition, it is considered a lignocellulosic material rich in proteins and fibers, $20 \%$ and $70 \%$ of its composition, respectively. It also contains approximately $17 \%$ cellulose, $28 \%$ hemicellulose and $28 \%$ lignin (Mussatto et al. 2006) [19]. For every 100 liters of beer produced, between 14 - $20 \mathrm{~kg}$ of malt bagasse are generated (Cordeiro, et al. 2012) [20].

The number of breweries in the country has a few hundred production units (MAPA, 2018) [21]. The large number of plants installed gives the idea of the enormous dimension that is generated from this waste. Thus, it can be said that the malt bagasse has the ideal characteristics to be studied as a biosorbent.

Studies using malt bagasse as a biosorbent have already been carried out by several authors, such as Zanutto, et al. (2016) [11], who evaluated malt bagasse as a biosorbent of reafix yellow dye B2R; and Fontana, et al. (2016) [8], who evaluated malt bagasse in the biosorption of metal ions present in ground and surface water. Thus, the present work, had as objective investigate and evaluate the capacity of malt bagasse as an acetic acid adsorbent as a potential potential for use in wastewater treatment systems.

\section{Methodology}

\subsection{Biomass Preparation}

The malt bagasse was initially washed with tap water, and then was left to soak for 24 hours in distilled water to remove possible impurities.

Then, the material was dried to avoid the proliferation of fungi, initially dried in the sun and subsequently dried in an oven at $70^{\circ} \mathrm{C}$ for 24 hours to remove excess moisture.

A possible stage of crushing the malt bagasse was dispensed with, since in their work, as presented by Zanutto, et al. (2016) [11], they point out that the 
granulometry of the malt bagasse has no influence on the biomass adsorption efficiency. This phenomenon is due to the fact that the malt bagasse has a shape similar to that of blades, thus, its surface area does not undergo significant change when it is fragmented into smaller pieces, since its lateral area is small when compared to its longitudinal area (Zanutto, et al. 2016) [11].

In this work, the following were studied: 1) study of the effect of biomass dosage; 2) study of the adsorption capacity, with the application of Langmuir and Freundlich isotherms to the experimental data; 3) kinetic study, applying the pseudo-first order, pseudo-second order models and 4) intra-particle diffusion model, from which it will be possible to elucidate some characteristics of the acetic acid adsorption mechanism in bagasse biomass malt, and determine its limiting step.

\subsection{Preparation of Solutions and Standardization}

The solutions of sodium hydroxide (Synth) and glacial acetic acid (Synth) used in the present work of analytical grade, were prepared and standardized as described below:

1) The sodium hydroxide solution $(0.2 \mathrm{M})$ was prepared by solubilizing analytical standard sodium hydroxide in the form of lentils in distilled water, followed by dilution in volumetric glassware.

2) The sodium hydroxide solution was standardized using a volumetric method with oxalic acid, using phenolphthalein as an indicator.

3) Acetic acid solutions (0.4 M, 0.36 M, 0.32 M, 0.28 M, 0.24 M, 0.20 M, 0.16 $\mathrm{M}, 0.12 \mathrm{M}, 0.08 \mathrm{M}, 0.04 \mathrm{M}$ e $0.01 \mathrm{M}$ ), were prepared by diluting $99.7 \%$ pure glacial acetic acid.

4) The acetic acid solutions were standardized using a volumetric method with sodium hydroxide, previously standardized, using phenolphthalein as an indicator.

\subsection{Biomass Concentration Influence Test}

To evaluate the influence of the concentration of malt bagasse in the removal of acetic acid, batch tests were carried out in $250 \mathrm{ml}$ Erlenmeyer flasks with respective lids, where $100 \mathrm{ml}$ of $0.4 \mathrm{M}$ acetic acid solution in contact with the biomass in mass/volume proportions varying between 1.25 to $70 \mathrm{~g} \cdot \mathrm{L}^{-1}$. This test was performed in duplicate for all concentrations of malt bagasse.

At room temperature $\left(25^{\circ} \mathrm{C}\right)$, the vials were subjected to manual agitation for the duration of the first minute of contact time, and subsequently subjected to manual agitation during the last minute of contact time. The total contact time between biomass and acetic acid solution was 24 hours.

After the end of the contact time, the samples were subjected to filtration with qualitative filter paper, in order to separate the solid phase from the liquid phase.

Then the residual concentration of acetic acid present in the filtrate, that is, the liquid phase was titrated with $0.2 \mathrm{M}$ sodium hydroxide. The efficiency re- 
lated to the amount of acetic acid that the biomass is able to adsorb was determined using Equation (5).

$$
q_{e}=\left(\frac{V}{m}\right) \cdot\left(C_{e}-C_{i}\right)
$$

where: $V$ is the volume of the solution (L), $\mathrm{m}$ is the mass of biosorbent $(\mathrm{g}), \mathrm{C}_{\mathrm{i}}$ and $C_{e}$ are the initial and equilibrium concentrations $\left(\mathrm{mg} \cdot \mathrm{L}^{-1}\right)$ respectively, $\mathrm{q}_{\mathrm{e}}$ is the amount of solute adsorbed per unit mass of adsorbent $\left(\mathrm{mg}^{-1} \mathrm{~g}^{-1}\right)$ in equilibrium.

\subsection{Kinetic Test}

In the evaluation of the kinetic study of the process in order to determine the necessary contact time between acetic acid and malt bagasse for the system to reach equilibrium, a kinetic test was carried out in which the amount of acetic acid adsorbed by the biosorbent in different time intervals during one hour of contact.

The samples were prepared in duplicate in $250 \mathrm{~mL}$ Erlenmeyers with respective lids, where a mass of malt bagasse was added, determined according to the result of the concentration influence test, that is, the amount of biomass and 100 $\mathrm{mL}$ of $0.04 \mathrm{M}$ acetic acid. A blank control sample was also prepared with only $100 \mathrm{~mL}$ of distilled water and malt bagasse.

After preparation, the samples, at room temperature $\left(25^{\circ} \mathrm{C}\right)$, were stirred manually during the first minute of contact, and subsequently stirred again during the last minute of contact. The samples were filtered with a qualitative filter and the filtrate titrated with sodium hydroxide at predetermined time intervals (from 0 to 60 minutes). In this way, the filtrate was analyzed in relation to the initial concentration of acetic acid in the liquid phase.

Finally, the results of this test allowed the determination of the equilibrium time in addition to the kinetic parameters of the acetic acid adsorption process in malt bagasse. The parameters were obtained by adjusting the experimental data to the kinetic models of Pseudo-First Order, Pseudo-Second Order and to the Intraparticle Diffusion Model, expressed by Equations (6)-(8), respectively.

The Lagergren pseudo-first order model is most commonly used to describe the adsorption of solute from a liquid solution.

$$
\frac{\mathrm{d} q_{t}}{\mathrm{~d} t}=k_{1}\left(q_{e}-q_{t}\right)
$$

where: $q_{t}$ and $q_{e}$ are the amounts of the analyte adsorbed at time $t$ and equilibrium $\left(\mathrm{mg}^{-1} \mathrm{~g}^{-1}\right)$, respectively, and $k_{1}$ is the pseudo-first order rate constant for the adsorption process $\left(\mathrm{L} \cdot \mathrm{min}^{-1}\right)$. After integration and applying boundary conditions $t=0$ to $t=t$ and $q_{t}=0$ to $q_{t}=q_{t}$.

The Lagergren pseudo-second order model, the rate limiting step is the surface adsorption that involves chemisorption, where the adsorbate removal from a solution is due to physicochemical interactions between the two phases, that is, liquid and solid phases. 


$$
\frac{\mathrm{d} q_{t}}{\mathrm{~d} t}=k_{2}\left(q_{e}-q_{t}\right)^{2}
$$

where: $q_{e}$ and $q_{t}$ in $\left(\mathrm{mg} \cdot \mathrm{g}^{-1}\right)$ are the amounts of acetic acid adsorbed per unit mass of the malt bagasse and at any contact time, respectively. $k_{2}$ is the equilibrium rate constant of pseudo-second order equation $\left(\mathrm{g} \cdot \mathrm{mg} \cdot \mathrm{min}^{-1}\right)$. For the boundary conditions $t=0$ and $t=t$ and $q_{t}=0$ and $q_{t}=q_{t}$.

Generally, the intraparticle diffusion model depends on several factors, such as the physical properties of the adsorbent, the initial concentration of the solution, temperature and agitation of the bath.

$$
q_{t}=k_{d} t^{1 / 2}+C
$$

where: $q$ is the adsorbed quantity of solute. $K_{d}\left(\mathrm{~L} \cdot \mathrm{min}^{-1}\right)$ is the intraparticle diffusion parameter, also known as the Lagergren pseudo-first order constant, as described by Srinivasa et al. (2010) [22], and $C$ is the thickness of the boundary layer.

\subsection{Chemical Equilibrium}

In this study, in order to determine the maximum adsorption capacity and the binding force of acetic acid by the malt bagasse, a chemical equilibrium study was carried out that demonstrate important characteristics of the adsorption phenomenon in question with the application of mathematical models of Langmuir and Freundlich.

The test was performed in duplicate using $250 \mathrm{~mL}$ erlenmeyers and adding malt bagasse mass determined according to the result obtained in the biomass concentration influence test, and $100 \mathrm{~mL}$ of acetic acid solutions with concentrations from 0.01 to $0.4 \mathrm{M}$, being divided into, $0.01 ; 0.04 ; 0.08 ; 0.12 ; 0.16 ; 0.20$; $0.24 ; 0.28 ; 0.32 ; 0.36 ; 0.40 \mathrm{M}$.

After preparing the samples at room temperature $25^{\circ} \mathrm{C}$, were subjected to manual agitation during the first minute of the contact time, resting and later they were stirred again during the last minute of contact, where the total contact time between the acetic acid solutions and the biosorbent, will be determined according to the results of the kinetic study of the adsorption process.

After the contact time, the samples were filtered on qualitative filter paper, and then the filtrate was titrated with $0.2 \mathrm{M}$ sodium hydroxide in order to determine the equilibrium acetic acid concentration in the liquid phase. In this way the filtrate was analyzed in relation to the initial concentration of acetic acid in the liquid phase, and the amount of acetic acid adsorbed per gram of biomass, $q_{e}$, can be determined by difference.

\section{Results and Discussion}

Initially, in order to determine the ideal amount of malt bagasse for the acetic acid adsorption process, the effect of biomass dosage was studied. Since the concentration of biomass in solution is one of the main factors that affect the biosorption process (Das et al., 2008) [23]. 
Based on the results expressed in Figure 3, it is possible to notice a decrease in the concentration of acetic acid in the liquid phase with an increase in the concentration of malt bagasse to a value close to $40 \mathrm{~g} \cdot \mathrm{L}^{-1}$, from which the concentration values of acetic acid in liquid phase are practically constant.

In this way, an ideal biomass concentration of approximately $40 \mathrm{~g} \cdot \mathrm{L}^{-1}$, can be identified, since the values of acetic acid concentration in liquid phase are considered constant from this biomass concentration range, if the concentration of the biosorbent increases, there is a decrease in the value of acetic acid adsorbed per unit weight of malt bagasse, even though the removal efficiency remains constant, as shown in the curve, as shown in Figure 4.

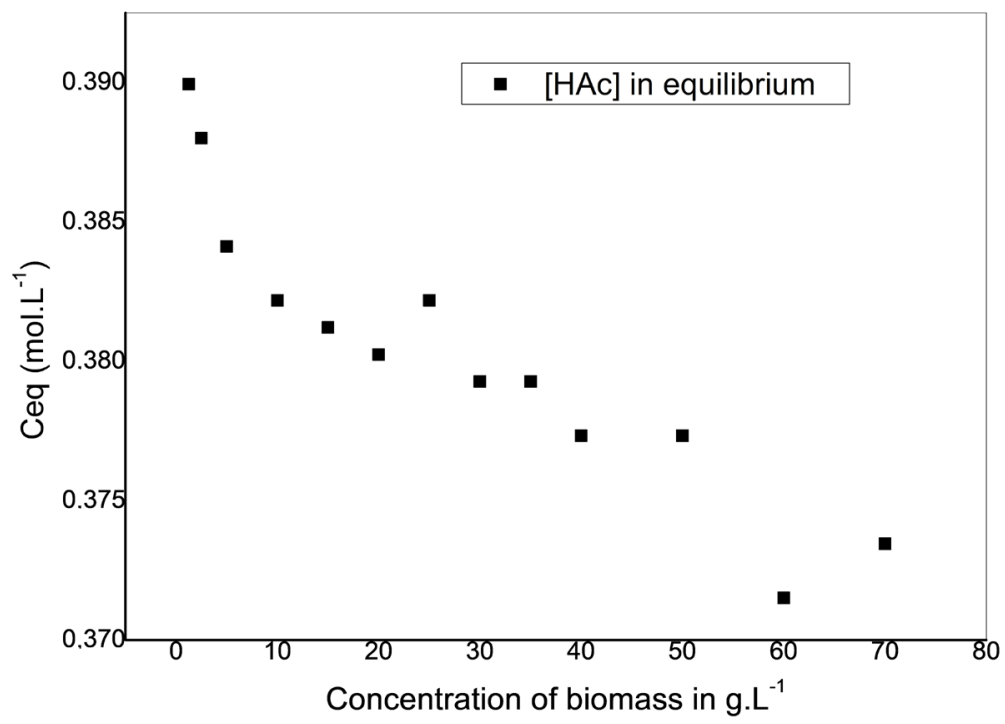

Figure 3. Equilibrium concentration of acetic acid in liquid phase (-) as a function of the amount of biomass.

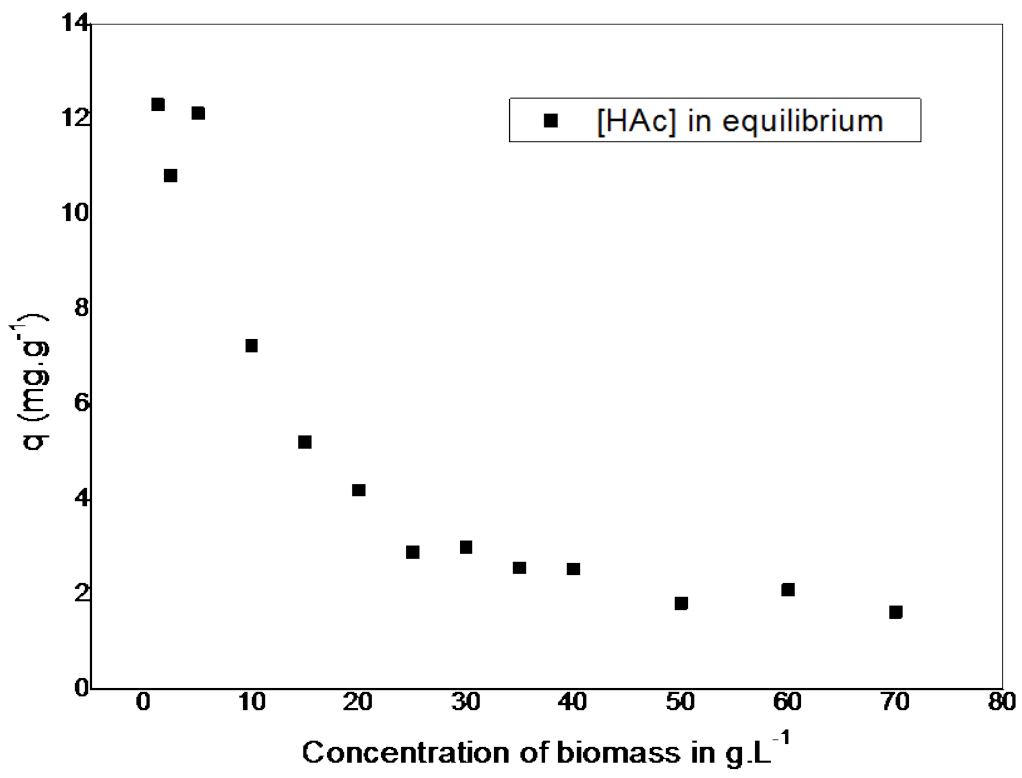

Figure 4. Amount of acetic acid adsorbed on solid phase (•). 
Thus, for an ideal concentration of $40 \mathrm{~g} \cdot \mathrm{L}^{-1}$ of biosorbent, there is a $4.3 \%$ removal with a removal capacity of $2.5 \mathrm{mg} \cdot \mathrm{g}^{-1}$ of biomass. However, it should be noted that these values are only for the purpose of tests to compare the adsorption capacity of different concentrations, that is, the amount of biomass and to determine the ideal amount of biosorbent, and are not real values of the adsorption capacity of acetic acid in malt bagasse. For real values of the acetic acid adsorption capacity in malt bagasse, larger results are observed, as demonstrated in the results of the equilibrium test of the adsorption process.

In order to determine the time necessary to reach the balance in the acetic acid adsorption process in malt bagasse biomass, the experiment was carried out, that is, the kinetic test.

As shown in Figure 5, a quick removal of acetic acid can be observed in the initial phase of the process, about $12.5 \%$ removal of acetic acid from the solution in the first 10 minutes of contact. And after the initial 10 minutes, the adsorption process begins to occur more slowly, until it reaches equilibrium in 20 minutes of contact, with a $17.5 \%$ removal of acetic acid from the liquid phase. It can also be observed that the points 30,50 and 60 minutes were out of mathematical adjustment due to the fact that represent experimental points that are susceptible to errors during the evaluation.

The kinetic behavior observed for the adsorption of acetic acid in malt bagasse is of relevance for the evaluation of malt bagasse in terms of its potential use for the removal of COD and BOD in effluent treatment, and the credence for such application in industrial processes. Therefore, rapid kinetics is important for wastewater treatment systems, where the retention time is a highly evaluated parameter. Rapid kinetics means less detention time, which means that with a

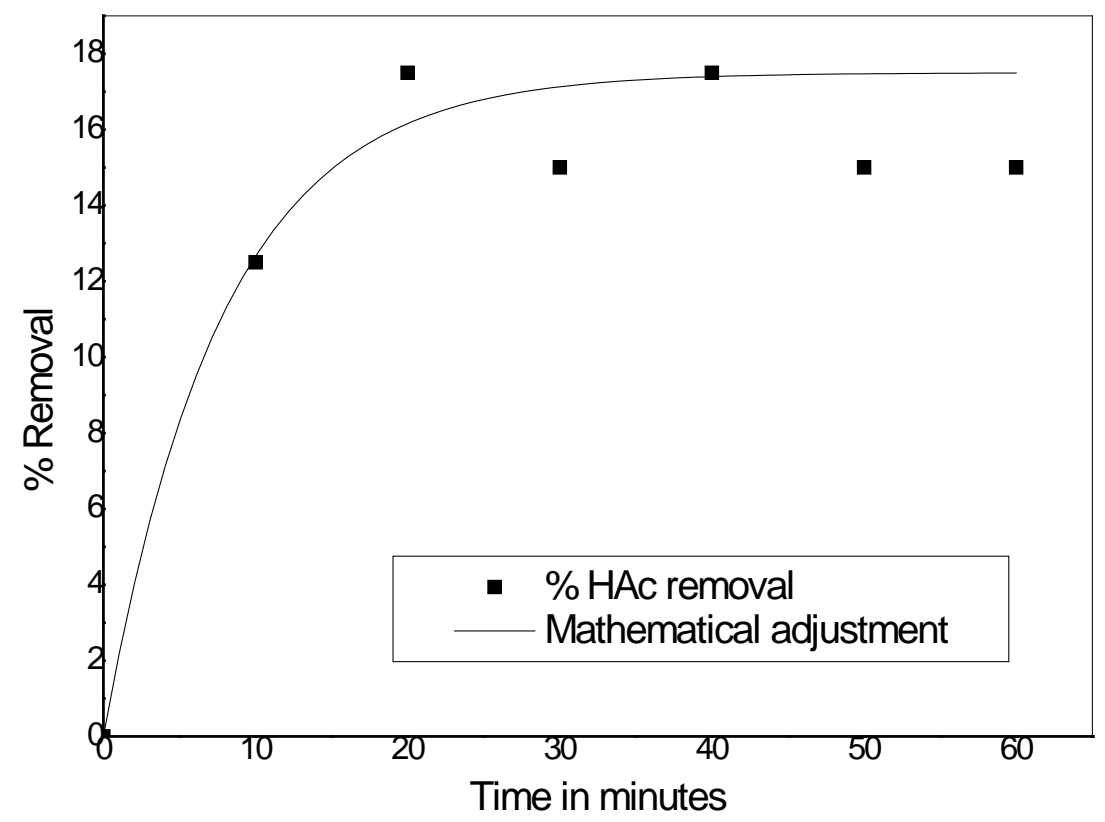

Figure 5. Percentage of removal of acetic acid (-) as a function of time and mathematical adjustment $(-)$. 
small volume reactor, large amounts of effluents can be treated, that is, larger amounts of effluents can be treated in short time intervals, which increases the system efficiency and consequent cost reduction.

Mendes, et al. (2015) [24], Fontana, et al. (2016) [8] and Zanutto, et al. (2016) [11], who carried out work using residues from the beer industry as a biosorbent, also observed the same kinetic characteristic of rapid removal in the initial phase of the process, followed by a decrease until the equilibrium time.

The adsorption kinetics occurs quickly in the beginning of the process due to the existence of a greater number of empty sites that are occupied, and during the time of contact, the number of empty sites decreases, while the repulsive forces increase, which makes it more difficult the occupation of neighboring sites (Zanutto, et al. 2016) [11].

In order to obtain more information on the acetic acid adsorption kinetics in malt bagasse and the adsorption rate as a function of time, as well as the Pseudo-First Order and Pseudo-Second Order parameters, the linearized forms of these models were applied mathematical to experimental data.

In the evaluation of the kinetic model that best represents the biosorption process of acetic acid in malt bagasse, it was performed based on the values of the correlation coefficients, as shown in Table 1 .

The plotting $\ln \left(q_{e}-q_{t}\right)$ as a function of $t$ provides a linear function from which the values of $K_{1}$ and $\mathrm{q}_{\mathrm{e}}$ are obtained from the slope and the intercept, respectively. Similar to $K_{2}$, plotting $t / q_{t}$ as a function of $t$.

The adjustment of the linearized forms of the Pseudo-First Order and Pseudo-Second Order models allowed the presentation of the experimental data presented in Figure 6 and Figure 7 respectively.

Based on the correlation coefficient $\left(R^{2}\right)$ obtained through the linear regression of the kinetic models adjusted to the experimental data, it is possible to determine the kinetic model to which the experimental values have the best mathematical adjustment. Table 2 shows the values of the correlation coefficients and the parameters obtained for each kinetic model, as well as the experimental value of the amount of acetic acid adsorbed in the equilibrium.

Observing the correlation coefficients in Table 3, it can be said that the kinetic model that has better adjustment to the experimental data is the Pseudo-Second Order model, whose correlation coefficient has a value of 0.9785 , much closer to the unit than the value of the correlation coefficient for the adjustment of the Pseudo-First Order model of 0.7489 . Also observing the other parameters, it can be noted that the value of $q_{e}$ obtained through linear regression for the Psudo-Second

Table 1. Linearized shapes of the kinetic models and plotting mode.

\begin{tabular}{ccc}
\hline Kinetic models & Linear shape & Plotting \\
\hline Pseudo-first order & $\ln \left(q_{e}-q_{t}\right)=\ln q_{e}-k_{1} t$ & $\ln \left(q_{e}-q_{t}\right)$ in function of $\boldsymbol{t}$ \\
Pseudo-second order & $\frac{1}{q_{t}}=\frac{1}{k_{2} q_{e}^{2}}+\frac{t}{q_{e}}$ & $t / q_{t}$ in function of $t$
\end{tabular}




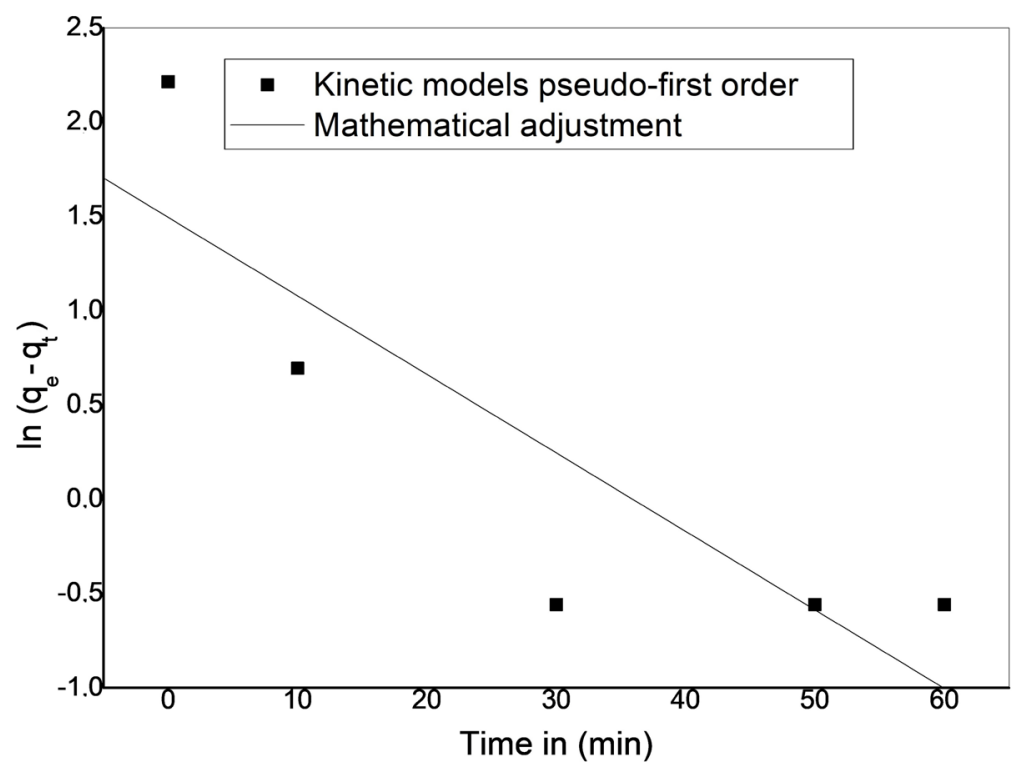

Figure 6. Pseudo-first order kinetic model adjusted to experimental data.

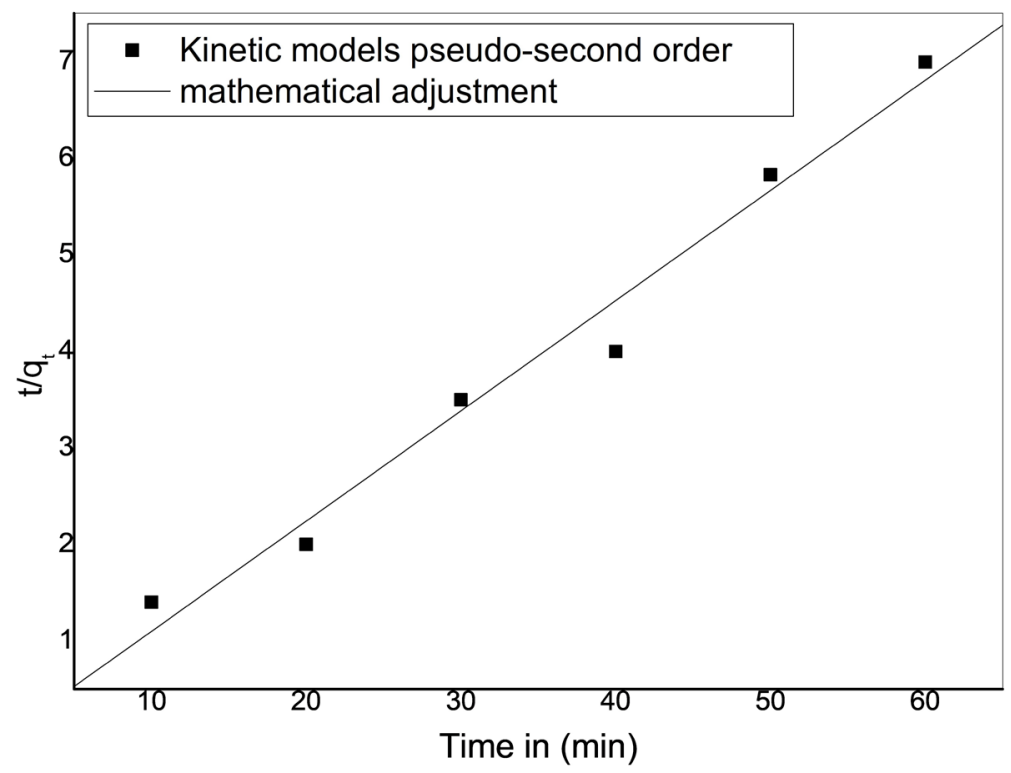

Figure 7. Pseudo-second order kinetic model adjusted to experimental data.

Table 2. Correlation coefficient and parameters of the kinetic models.

\begin{tabular}{ccc}
\hline Kinetic Models & Parameters \\
\hline Pseudo-first order & $K_{1}\left(\mathrm{~min}^{-1}\right)$ & -0.0416 \\
$\ln \left(q_{e}-q_{t}\right)=\ln q_{e}-k_{1} t$ & $q_{e}\left(\mathrm{mg}^{-1}\right)$ & 4.4602 \\
& $R^{2}$ & 0.7489 \\
Pseudo-second order & $\mathrm{K}_{2}\left(\mathrm{~g} \cdot \mathrm{mg}^{-1} \cdot \mathrm{min}^{-1}\right)$ & -0.2936 \\
$\frac{1}{q_{t}}=\frac{1}{k_{2} q_{e}^{2}}+\frac{t}{q_{e}}$ & $\mathrm{qe}_{e}\left({\left.\mathrm{mg} \cdot \mathrm{g}^{-1}\right)}^{R^{2}}\right.$ & 8.7581 \\
Experimental Data & $q_{e}\left(\mathrm{mg} \cdot \mathrm{g}^{-1}\right)$ & 0.9785 \\
$t(20 \mathrm{~min})$ & $C_{e}\left(\mathrm{~mol} \cdot \mathrm{L}^{-1}\right)$ & 9.15102 \\
& & 0.0320
\end{tabular}


Table 3. Parameters of the intra-particle diffusion model.

\begin{tabular}{cccc}
\hline Parâmetros & Etapa I & Etapa II & Etapa III \\
\hline$K_{d}\left(\mathrm{mg} \cdot \mathrm{g}^{-1} \cdot \mathrm{min}^{-1 / 2}\right)$ & 2.18321 & 1.68747 & 0 \\
$C\left(\mathrm{mg} \cdot \mathrm{g}^{-1}\right)$ & 0.24532 & -0.66359 & 8.57909 \\
$\mathrm{R}^{2}$ & 1 & 1 & 1 \\
\hline
\end{tabular}

Order model is much more consistent with the experimental value of $q_{e}$ presenting a relative error in relation to the experimental value of $q_{e} 4.29 \%$ against $51.26 \%$ of the Pseudo-First Order model.

Almeida et al. (2018) [25], who studied the removal of reactive dye using malt bagasse as a biosorbent in a batch system, obtained similar results for the adjustment of experimental data to kinetic models, where they were better adapted to the Pseudo-Second Order model than to the model of Pseudo-First Order. As well as Zanutto, et al. (2015) [26] and Zanutto, et al. (2016) [11], who studied the application of malt bagasse as a biosorbent for dyes, and obtained higher values of correlation coefficient for adjusting the Pseudo-Second Order kinetic model to the data experimental.

In the search for information related to the adsorption mechanism and to determine the limiting step in the process of biosorption of acetic acid in malt bagasse, as well as to determine if the process is controlled by only one or more than one step, the Model of Intra-particle diffusion to experimental data.

According to Equation (8), where $q_{t}\left(\mathrm{mg}^{\mathrm{g}} \mathrm{g}^{-1}\right)$ is the amount of acetic acid adsorbed in the malt bagasse biomass in time $t$ and $k_{d}\left(\mathrm{mg} /\left(\mathrm{g} \cdot \mathrm{min}^{1 / 2}\right)\right.$ is the constant of the intra-diffusion rate plotting experimental data $q_{t}$ versus $t^{1 / 2}$ were used to determine the intra-particle diffusion rate ( $k_{d}$, i.e. the slope), correlation coefficient $R^{2}$, and the intra-particle diffusion constant at $\left(\mathrm{mg} \cdot \mathrm{g}^{-1}\right)$ the constant $C$, that is, the intercept, related to the thickness of the boundary layer, therefore, the larger the intercept, the greater the effect of the boundary layer (Tan, et al. 2010) [27].

In Figure 8, it is possible to observe a multilinearity correlation that reveals more than one step occurred during the adsorption process.

Considering step (I) being the diffusion through the solution to the external surface of the adsorbent, that is, the initial linear portions, which is also known as external mass transfer or film diffusion, according to (Walker, et al. 2003) [28], while step (II) corresponds to the intra-particle diffusion in the porous structure of the adsorbent (Abbek-Ghani, et al. 2015) [29]. The last horizontal portions, stage (III) slowly and controlled by the equilibrium diffusion mechanism (Diagboya, et al. 2014) [30].

Since the Weber-Morris graph ( $q_{t}$ versus $\left.t^{1 / 2}\right)$ is linear, then intra-particle diffusion occurs for the process. And yet, if the line passes through the origin, then intra-particle diffusion is the only rate-limiting step (Suteu, et al. 2013) [31].

In the present study, the experimental data applied to the intra-particle diffusion model did not pass through the origin, as shown in Figure 8, indicating that the 


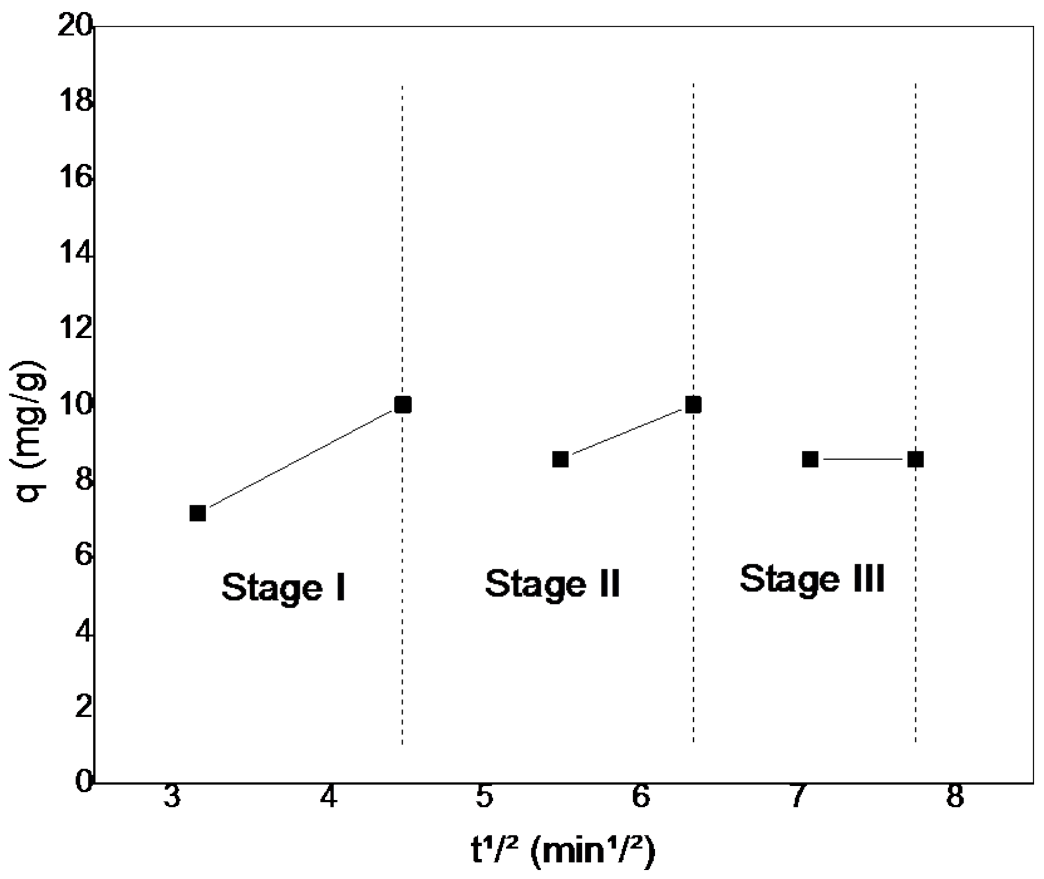

Figure 8. Application of the intra-particle diffusion model adjusted to the experimental data to the acetic acid adsorption process in malt bagasse.

intra-particle diffusion is not the only limiting step, but the diffusion of the film also plays an important role in adsorption. This situation coincides with the fact that adsorption processes follow the pseudo-second order model (Nethaji, et al. 2013) [32].

Table 3 presents the values of the parameters of the Intraparticle Diffusion Model obtained for each stage of the acetic acid adsorption process in malt bagasse biomass.

Another point to note is that the constant $K_{d}$ (corresponds to the slope of the graph) of the first step is the largest when compared to the other steps, which indicates a higher rate of change of $\mathrm{q}$ as a function of the $t^{1 / 2}$, i.e., the first step is the quick step in the biosorption process in question. It is known that the limiting step of a process is the one with the lowest rate of variation (lowest slope), that is, for the case in question it is the one with the lowest $K_{d}$ value.

Observing the results, it is noted that the lowest $K^{d}$ value corresponds to the third stage, however, this stage corresponds to the state of equilibrium. In this way, it can be deduced that the second step, with a second lower slope, that is, 1.68747 corresponds to the limiting step of the biosorption process, a step which according to Fontana, et al. (2016) [8], is controlled by the intra diffusion mechanism-particle, which corresponds to the intra-particle diffusion in the porous structure of the adsorbent.

The adsorption isotherms provide important information about the studied biosorption process, such as, for example, if the process in question is favorable or unfavorable, as well as the maximum adsorption capacity. Thus, in order to obtain more information about the acetic acid biosorption process in malt ba- 
gasse, the balance test was carried out, being adjusted to the Langmuir and Freundlich models. Having the equilibrium time determined, the equilibrium test duration to obtain the adsorption isotherm would need only 20 minutes, necessary for the process to reach equilibrium, however, for optimization of the experimental time, it was preferred to leave a time of upper contact, 6 hours.

The experimental results obtained were expressed in the form of the Graph shown in Figure 9.

Observing the trend curve of the experimental data in Figure 9, it is noted that the isotherm in question takes on a concave shape similar to the Langmuir isotherm. Thus, it is expected that the Langmuir model fits better to the experimental data than Freundlich's. In addition, the process in question is expected to be strongly favorable.

Through mathematical adjustment, the experimental data were applied to the linearized forms of the Langmuir and Freundlich isotherms, obtaining Figure 10 and Figure 11 respectively.

From the linear regression equations, the correlation coefficients $\left(R^{2}\right)$ were obtained, as well as the Langmuir and Freundlich parameters, and are shown in Table 4.

In observing the correlation coefficients obtained in the adjustment of the experimental values to the Langmuir and Freundlich models, it can be verified which model best represents the acetic acid adsorption process in malt bagasse. But it is noted that the Langmuir model obtained a better fit to the experimental data, representing $75.176 \%$, while the adjustment to the Freundlich model represented $74.590 \%$. It is also observed that the value of $q_{m}$ obtained through

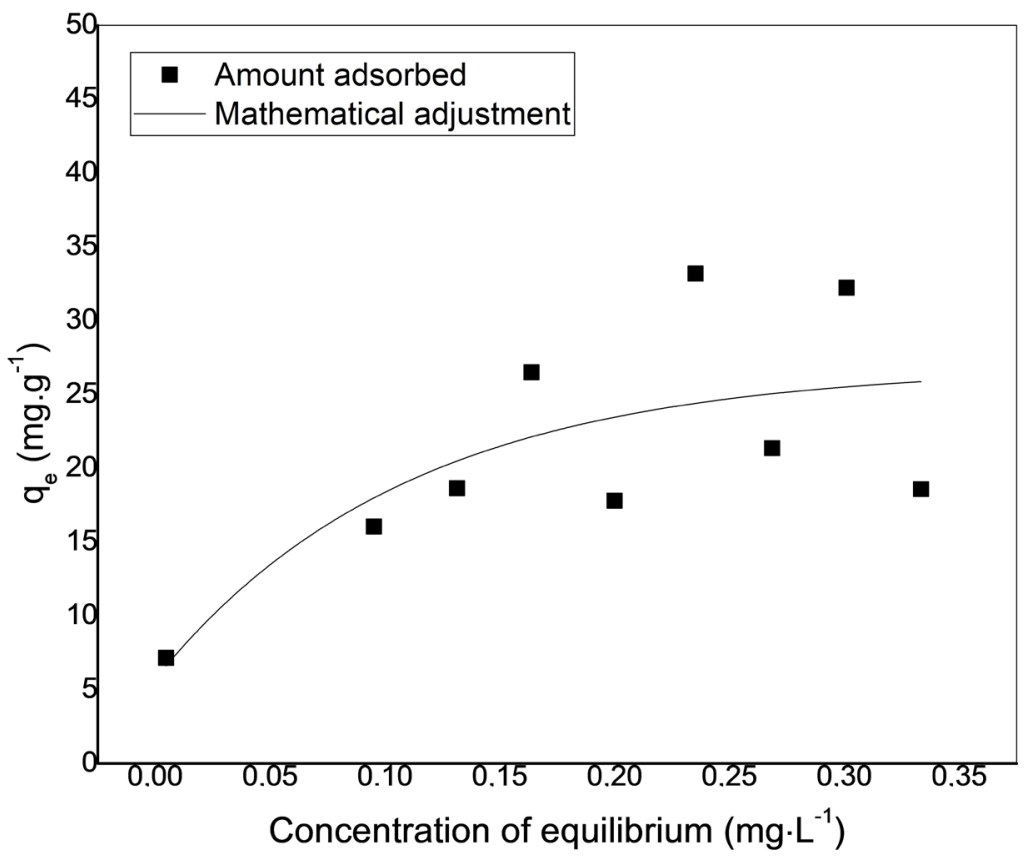

Figure 9. The amount adsorbed $q_{e}(\cdot)$ as a function of the concentration of acetic acid in the equilibrium and mathematical adjustment to the experimental points (-). 


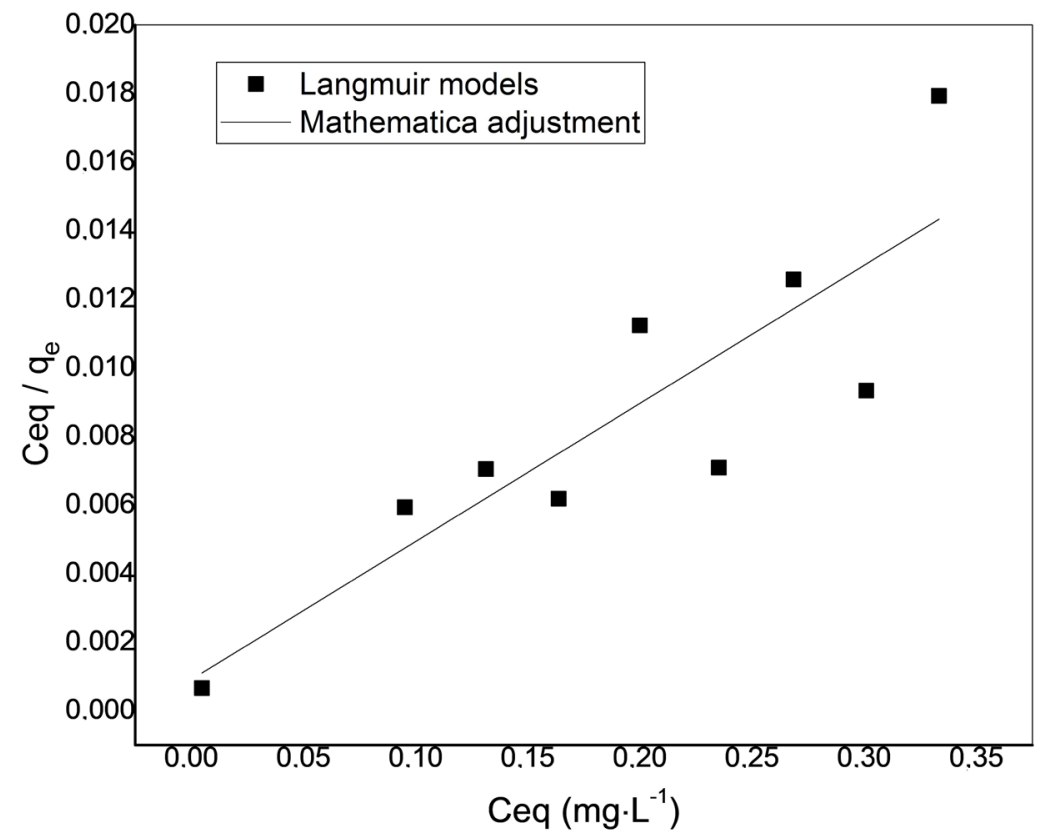

Figure 10. Langmuir linear equation adjusted to experimental data.

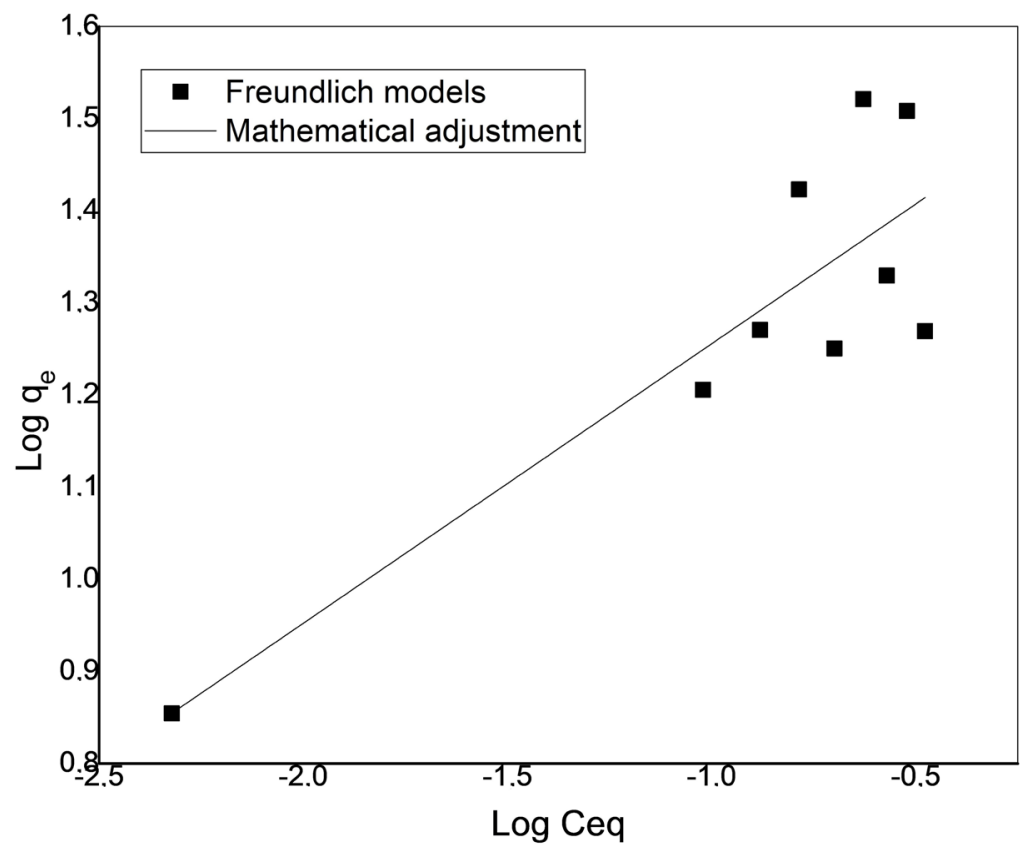

Figure 11. Freundlich linear equation adjusted to experimental data.

Table 4. Correlation coefficient and parameters of the Langmuir and Freundlich models.

\begin{tabular}{cccc}
\hline \multirow{2}{*}{ Isotherms } & \multicolumn{2}{c}{ Parameters } & Correlation coefficients $\left(R^{2}\right)$ \\
\hline \multirow{2}{*}{ Langmuir } & $q_{m}\left(\mathrm{mg} \cdot \mathrm{g}^{-1}\right)$ & 24.8324 & 0.75176 \\
& $K_{L}\left(\mathrm{~L} \cdot \mathrm{mg}^{-1}\right)$ & 44.2478 & \\
\multirow{2}{*}{ Freundlich } & $n$ & 3.29674 & 0.74590 \\
& $K_{F}\left(\mathrm{~g}^{-1}\right)$ & 36.2193 & \\
\hline
\end{tabular}


linear regression for the Langmuir model is relatively close to the real value of $\left(q_{e}\right)$ at approximately $25 \mathrm{mg} \cdot \mathrm{g}^{-1}$, as shown in Figure 9.

Even so, it should be noted that the value obtained for the correlation coefficient of fitting the Langmuir model [13] to the experimental data is low. However, it is seen that in the literature, many of the authors who carried out studies of the adsorption isotherm in malt bagasse biomass, obtained better adjustments of the Langmuir model to the experimental data than of the Freundlich model [15]. This observed phenomenon can be explained possibly based on the composition of the malt bagasse, which is mainly composed of lignin and cellulose, which have functional groups that can serve as ion exchangers for the adsorption of acetic acid in specific sites.

This result is an indication that the acetic acid biosorption process in malt bagasse takes place through chemical adsorption at specific sites and with the formation of a monolayer. But it should be noted that a high value for $n=$ 3.29674, indicates a major change in effectiveness over different equilibrium concentrations, that is, the closer to zero the value of $(1 / n=0.30332)$ is presented, greater affinity the adsorbent will have for the adsorbent. In addition, values of $n>1$ indicate that the adsorption process takes place in multilayers (Aygun, et al. 2003) [33].

However, the result obtained points out that the acetic acid adsorption process takes place according to the Langmuir model, that is, the adsorption process occurs in monolayer and assumes that the surface is homogeneous.

The isotherm obtained experimentally indicates that the phenomenon of biosorption is highly favorable, and this is a sign of a great potential of the malt bagasse for use as a biosorbent, in the removal of organic matter in the treatment of effluents.

\section{Conclusions}

The ideal concentration of $40 \mathrm{~g} \cdot \mathrm{L}^{-1}$ of malt bagasse is verified for the adsorption of acetic acid based on the test of the influence of the biomass concentration.

The kinetic test allowed us to conclude that the acetic acid adsorption process in malt bagasse has a fast kinetics, reaching equilibrium in a time interval of up to 20 minutes, which favors its use in effluent treatment systems, since it demands a shorter detention time due to its fast kinetics.

The adjustment of kinetic models to experimental data showed that the Pseudo-Second Order kinetic model better represents the acetic acid adsorption process in malt bagasse than the Pseudo-First Order model. And the adjustment of the Intra-particle Diffusion Model, allowed identifying the limiting step of the adsorption process as I feel the intra-particle diffusion, however, the multilinearity of the results shows that this is not the only step that controls the biosorption mechanism in question.

The adjustment of Freundlich's Langmuir models to the results obtained from the balance test allowed us to identify that the phenomenon of biosorption of 
acetic acid by malt bagasse is better represented by the Langmuir model than by the Freundlich model, which is an indication that the chemical adsorption in monolayer governs the studied biosorption process. The process is thus shown to be strongly favorable and with a good adsorption capacity.

Thus, the malt bagasse has great potential to be used as a biosorbent in the removal of acetic acid in wastewater treatment systems. However, the efficiency obtained by this biosorption process, approximately $30 \mathrm{mg} \cdot \mathrm{g}^{-1}$, is not sufficient to meet the current legislation in terms of COD removal. Thus, in order to be used in the treatment of effluents, the process of biosorption in malt bagasse should be combined with other existing technologies, such as, for example, anaerobic upflow reactor (RUFA) and activated sludge system, which would increase the ability to remove COD and BOD from these technologies, in addition to increasing the efficiency of the effluent treatment system in terms of volume of effluent treated per hour.

\section{Acknowledgements}

The authors would like to thank the Department of Chemistry at the Federal University of Rondônia for the space for the development and evaluation of the research.

\section{Conflicts of Interest}

The authors declare no conflicts of interest regarding the publication of this paper.

\section{References}

[1] Cammarota, M.C. (2011) EQB-485 Environmental Engineering. Lecture Notes: Treatment of Liquid Effluents, Vol. 3, School of Chemistry/UFRJ, Rio de Janeiro.

[2] Silveira, G.E. (2010) Industrial Effluent Treatment Systems. Course Conclusion Paper-Chemical Engineering Course, Federal University of Rio Grande of South (UFRGS), Porto Alegre.

[3] Izquierdo, B.K.H. (2006) Study of the Behavior of a System of Activated Sludge with a Moving Bed Reactor (MBBR). Dissertation (Master's Degree), Civil Engineering Course, Federal University of Rio de Janeiro, Rio de Janeiro.

[4] CONAMA, National Council for the Environment (2011) Resolution No. 430 of May 13.

[5] Adamian, R. and Almendra, E. (2002) Physical Chemistry: An Application to Materials. COPPE/UFRJ, Rio de Janeiro.

[6] Nascimento, R.F., Lima, A.C.A., Vidal, C.B., Melo, D.Q. and Raulino, G.S.C. (2014) Adsorption: Theoretical Aspects and Environmental Applications. Federal University of Ceará (UFC), Fortaleza.

[7] Atkins, P. and Paula, J. (2002) Physicochemical. 7th Edition, LTC, São Paulo.

[8] Fontana, I.B. and Cechinel, M.A. (2016) Use of Residues from the Cevejeira Industry in the Biosorption of Metal Ions Present in Ground and Surface Waters. Course Conclusion Paper-Chemical Engineering Course, University of the Extreme South of Santa Catarina (UNESC). 
[9] Weber, W.J. and Smith, J.M. (1987) Simulation and Design Models for Adsorption Processes. Environmental Science \& Technology, 21, 1040-1050. https://doi.org/10.1021/es00164a002

[10] Peternele, W.S. (1999) Adsorption and Desorption of $\mathrm{Cd}(\mathrm{II})$ and $\mathrm{Pb}$ (II) Ions in Functionalized Formic Lignin Obtained from Sugarcane Bagasse. Dissertation Chemistry Course, State University of Maringá (UEM), Maringá. https://doi.org/10.1016/S0960-8524(98)00083-2

[11] Zanutto, A. and Silva, B.C. (2016) Evaluation of Malt Bagasse as a Biosorbent of Reafix B2R Yellow Dye. Course Conclusion Paper-Chemical Engineering Course, Federal Technological University of Paraná (UTFPR), Ponta Grossa.

[12] Oliveira, S.P. (2013) Removal of Reactive Blue Dye 5g Using the Commercial Adsorbent Dowex $^{\mathrm{Tm}}$ Optipore $^{\mathrm{Tm}}$ sd-2. Dissertation (Master's)—Chemical Engineering Course, Center for Engineering and Exact Sciences, State University of Western Paraná (UNIOESTE), Toledo.

[13] Langmuir, I. (1918) The Adsorption of Gases on Plane Surfaces of Glass, Mica, and Platinum. Journal of the American Chemical Society, 40, 1361-1403. https://doi.org/10.1021/ja02242a004

[14] Adamson, A.W. (1976) Physical Chemistry of Surfaces. John Wiley \& Sons, Hoboken, Chap. 9.

[15] Freundlich, H.M.F. (1906) Over the Adsorption in Solution. Journal of Physical Chemistry, 57, 385-470.

[16] Castellan, G.W. (1976) Physicochemistry. Inter-American Educational Fund, Rio de Janeiro, Chap. 18.

[17] Noll, K.E., Gounaris, V. and Hou, W. (1992) Adsorption Technology for Air and Water Pollution Control. Lewis Publishers, Chelsea.

[18] Gadd, G.M. (2009) Biosorption: Critical Review of Scientific Rationale, Environmental Importance and Significance for Pollution Treatment. Journal of Chemical Technology \& Biotechnology, 84, 13-28. https://doi.org/10.1002/jctb.1999

[19] Mussatto, S.I., Dragone, G. and Roberto, I.C. (2006) Brewers' Spent Grains: Generation, Characteristics and Potential Applications. Journal of Cereal Science, 4, 1-14. https://doi.org/10.1016/j.jcs.2005.06.001

[20] Cordeiro, Luana, G., El-Aouar, A.A. and Gusmão, R.P. (2012) Characterization of Malt Bagasse from Breweries. Revista Verde, Mossoró (RN), 7, 20-22.

[21] MAPA-Ministério da Agricultura, Pecuária e Abastecimento (2018) Brasília-Brazil. https://ousejacerveja.com/brasil-fecha-2018-com-889-cervejarias/2019

[22] Srinivasa, R.K., Arnand, S. and Venkateswarlu, P. (2010) Adsorption of Cadmium(II) Ions from Aqueous Solution by Tectona grandis (Teak Leaves Powder). Bioresources, 5, 438-458.

[23] Das, N., Vimala, R. and Karthika, P. (2008) Biosorption of Heavy Metals-An Overview. Indian Journal of Biotechnology, 7, 159-169. https://doi.org/10.1016/j.is.2009.02.003

[24] Mendes, C.R., Dilarri, G. and Pelegrini, R.G. (2015) Application of the Biomass Saccharomyces cerevisiae as an Adsorbent Agent of the Direct Orange 2GL Dye and the Possible Mechanisms of Adsorbate/Adsorbent Interactions. Journal of Materials, Rio de Janeiro $(R)$, 20, 898-908. https://doi.org/10.1590/S1517-707620150004.0095

[25] Almeida, N.K.S., Gonçalves, G.C., Furtado, D.F. and Veit, M.T. (2018) Reactive Dye Removal Using Malt Bagasse as a Biosorbent in a Batch System. 12th Brazilian 
Meeting on Adsorption, Gramado, 2018, 1-8.

[26] Zanutto, A., Silva, B.C., Duarte, E.R., Almeida, L.N.B. and Pietrobelli, J.M.T.A. (2015) Kinetic Evaluation of Malt Bagasse in the Removal of the Reactive Yellow Dye. 11 th Brazilian Congress of Chemical Engineering in Scientific Initiation, Campinas, 2015, 302-307.

[27] Tan, I.A.W. and Hameed, B. (2010) Adsorption Isotherms, Kinetics, Thermodynamics and Desorption Studies of Basic Dye on Activated Carbon Derived from Oil Palm Empty Fruit Bunch. Journal of Applied Sciences, 10, 2565-2571. https://doi.org/10.3923/jas.2010.2565.2571

[28] Walker, G.M., Hansen, L., Hanna, J.A. and Allen, S.J. (2003) Kinetics of a Reactive Dye Adsorption onto Dolomitic Sorbents. Water Research, 37, 2081-2089. https://doi.org/10.1016/S0043-1354(02)00540-7

[29] Abdel-Ghani, N.T., El-Chaghaby, G.A. and Zahran, E.M. (2015) Pentachlorophenol (PCP) Adsorption from Aqueous Solution by Activated Carbons Prepared from Corn Wastes. International Journal of Environmental Science and Technology, 12, 211-222. https://doi.org/10.1007/s13762-013-0447-1

[30] Diagboya, P.N., Olu-Owolabi, B.I. and Adebowale, K.O. (2014) Microscale Scavenging of Pentachlorophenol in Water Using Amine and Tripolyphosphate-Grafted SBA-15 Silica: Batch and Modeling Studies. Journal of Environmental Management, 146, 42-49. https://doi.org/10.1016/j.jenvman.2014.04.038

[31] Suteu, D. and Malutan, T. (2013) Industrial Cellolignin Waste as Adsorbent for Methylene Blue Dye from Aqueous Solutions. Bioresource, 8, 427-446.

https://doi.org/10.15376/biores.8.1.427-446

[32] Nethaji, S., Sivasamy, A. and Mandal, A.B. (2013) Adsorption Isotherms, Kinetics and Mechanism for the Adsorption of Cationic and Anionic Dyes onto Carbonaceous Particles Prepared from Juglans regia Shell Biomass. International Journal of Environmental Science and Technology, 10, 231-242. https://doi.org/10.1007/s13762-012-0112-0

[33] Aygun, A., Yenisoy-Karakas, S. and Duman, I. (2003) Production of Granular Activated Carbon from Fruit Stones and Nutshells and Evaluation of Their Physical, Chemical and Adsorption Properties. Microporous and Mesoporous Materials, 66, 189-195. https://doi.org/10.1016/j.micromeso.2003.08.028 